\title{
Quo Vadis? Science and Regulation as Uneasy Bedfellows
}

\author{
J. Ian Blenkharn ${ }^{*}$
}

Blenkharn Environmental, 18 South Road, Ealing, London W5 4RY, UK

\begin{abstract}
In the waste management field and the wider environmental sciences arena, science and regulation have become increasingly uneasy bedfellows. Scientific research should create the bedrock that underpins environmental legislation, shaping its construction, interpretation and implementation. It is the currency of investment in the future of waste management. Society must be assured that scientific knowledge has been subject to rigorous peer review to ensure its credibility and high standard. The architects of our waste management legislation must be similarly rigorous and fully transparent in their application of that knowledge and its use in the shaping of the legislative framework.

The interface of science and policy presents both opportunities and challenges. Imposing penalties under regulations structured without satisfying a reasonable burden of scientific proof in their construction is questionably as wrong as seeking prosecution without evidence of fact. Science has its own professional standards and a universal Code of Practice for scientific conduct to which all investigators must adhere. Regulators must do likewise, to ensure that the need for an effective scientific foundation to legislation is properly met at all times, managed effectively and applied objectively and with uniformity.
\end{abstract}

In the waste management sector, research funding is often hard to find. But for those who succeed, the first goal will be publication of their findings in a suitable scientific journal. Despite the paucity of research funding, many highly respected scientific journals are now available, each imposing rigorous pre-publication peer-review. Subsequent critical appraisal of published findings among the research community identifies and filters out weak data, and provides a firm foundation for future transitional and applied research studies, and for commercial exploitation.

Published scientific research creates the bedrock that should underpin environmental legislation, shaping its construction, interpretation and eventual implementation. It is the currency of investment in the future of waste management, and of environmental protection. To be effective, Parliament and public alike must be assured that knowledge has been subject to rigorous peer review to ensure its credibility and high standard. Evidence-based legislation built upon this foundation should be precise and effective, though in reality Parliament generally relies upon its regulatory agencies, and the Courts, to shape its subsequent interpretation and to develop and set limits that define constraints on matters that are not implicitly specified by the original architects of our legislation.

But all is not well. The Royal Society questioned the credibility of this process at its highest level. As the UK's national scientific academy, the Royal Society is dedicated to promoting excellence in science, plays an influential role in national and international science policy, and provides advice to government and policymakers. In 2006, the Royal Society expressed concern about anecdotal evidence and a lack of objective scientific data in a report that was likely to

*Address correspondence to this author at the Blenkharn Environmental, 18 South Road, Ealing, London W5 4RY, UK; Tel: +44 (0)208 569 8316; Fax: +44 (0)208 847 5994; E-mail: blenkharn@ianblenkharn.com influence changes to EU legislation, highlighting with particular concern the use of scientific data that was not critically and independently reviewed, and corresponding failures in transparency.

Scientific expertise must play a critical role in shaping the legislative framework and the regulatory decisionmaking process applicable to environmental law. Where the detail that underlies legislation is not properly evidence based, such legislation is almost certainly set to fail. Regulators must seek information from a range of sources, commissioning additional studies when the knowledge base is inadequate or incomplete. Investigators must be independent from the regulatory agencies and demonstrably impartial, selected by open competition with careful scrutiny of their research proposals, independence and expertise judged by an independent panel of leading experts drawn from the wider scientific community. Reliance only on the in-house research of the regulatory agencies fails to ensure the rigour and research quality of the academic community. Avoiding completely the additional challenge of independent peer-review that forms an essential part of the publication process this may cast doubt on the legitimacy of the findings, and of any regulatory actions that are based upon them. This defeats the obligation to transparency and must be avoided.

Where circumstances demand early intervention, professional judgement may provide the sole criterion for action, but in such circumstances further studies must be commissioned and decisions revisited as soon as additional information becomes available. Nothing should be written in stone. Scientific investigators, regulators and reviewers must exercise discretion in deciding which studies to emphasize, which to consider but not rely upon too heavily, and which to eliminate, before taking action based upon the overall weight of evidence. That duty imparts a deep responsibility. Both science and law depend on rigorous review and penetrating critique to legitimise and perfect work done in their 
respective fields. Science and law may differ dramatically, however, in whom they trust to conduct this review. Science insists on vetting by disinterested reviewers whose only aim is to establish objective fact. Law, by contrast, favours input from persons who have a strong stake in the outcome. Most would favour a balanced approach combining the best attributes of each process. The highest standards of integrity and complete transparency are in equal part essential.

The regulatory agencies owe a similar debt in their implementation of existing legislation, in the construction of ancillary Codes of Practice and operational standards, and in Licensing etc. These tasks must be accurately researched, evidence-based, carefully standardised and fully transparent in their construct and application. The views and opinions of stakeholders must be sought through extensive consultation. Finally, statutory duties must be discharged with integrity, and with the assurance of uniformity in application.

In the UK, the Environment Agency and its Scottish equivalent, the Scottish Environment Protection Agency, together with central government and its research councils, each commission original and applied research in addition to their own in-house studies. There is, however, a substantial and increasingly apparent trend toward a process of regulation predicated largely on a limited or incomplete knowledge base, heavily influenced by prejudice and administrative convenience. The bedrock of science is increasingly set aside in favour of ideology and assumption, to be replaced with dogma and a flow of ex-Cathedra statements that cannot easily be questioned or formally challenged. Regulators may seek support from their own in-house studies though the value of these is generally compromised lack of independence and scientific rigour.

The issues are three fold:

$\bullet$

A failure to apply objective scientific principles to the construction of Regulations, Codes and Standards etc, which on occasions owe more to opinion than fact, and omit strong reference to science. This may include a reluctance to acknowledge the existence of uncertainty and deficiencies in the existing knowledge base, and a corresponding failure to commission further research where uncertainty exists

- $\quad$ A failure to adopt an open evidence-based approach to regulation. This goes hand in hand with a corresponding failure in transparency when evaluating data that is not subject to the critical appraisal achieved through research independence and peer review, and which otherwise might be misinterpreted or misrepresented by inappropriate extrapolation

- $\quad$ Failures that result in the wide disassociation of science and policy from the day-to-day undertaking of the regulatory role, with a lack of uniformity, structure and coherence in the routine application of statutory duty

Though such deficiencies are by no means universal, this is becoming increasingly common in the UK and elsewhere. Together, these issues conspire to undermine public or professional confidence. It would be inappropriate to omit praise for the many regulatory duties that are discharged efficiently and effectively. Sadly, however, the loss of re- spect in some areas denigrates the remainder of the service in the eyes of stakeholders and the public.

The regulatory agencies operate vicariously, through their hierarchical network of regional and local officers. A combative style is not uncommon, and this intensifies the friction and mis-trust, and strengthens barriers to communication, that may develop between regulator and those who are, and must be, regulated. Once written in "tablets of stone" there is a particularly unhealthy tendency for matters defined upon flimsy or incomplete evidence or assumption to acquire a veneer of respectability, to be presented as fact, and to be defensively ring-fenced against further critical review. Many would concur that extensive root and branch review and reform of operating policy is essential now in order to rectify these deficiencies [1]. Approved guidance documentation or a more formal Code of Practice generally supports legislation. As with core legislation, this additional material must be accurately constructed to guide and inform users of their regulatory obligations and the practical measures necessary to comply. Even here, serious errors are not unknown [2].

The interface of science and policy presents both opportunities and challenges. A failure to inform decisions with scientific insights, in an open and fully transparent manner, degrades the role of the regulatory agencies. Science and regulation become uneasy bedfellows. Imposing penalties under regulations structured without satisfying a reasonable burden of scientific proof in their construction is questionably as wrong as seeking prosecution without evidence of fact. In contrast, pressures for 'sound science' create an environment in which interested parties can demand more and more data and repeated scientific review, with the sole purpose of delaying the adoption of essential key standards and controls. This is equally unacceptable and must be prevented. And we must acknowledge that science itself may be flawed - from thalidomide, cold fusion and still more recent quackery, to the development of macerated sheep tissue as feed for cows that delivered to us the horrors of bovine spongiform encephalitis (BSE), science has sometimes severe limitations but cannot be abandoned in favour of a void filled only by opinion, guesswork and prejudice. Uncertainty in science, which is the norm and not the exception, does not mean that science is flawed. Rather, uncertainty should be a prompt for further and more detailed investigation [3].

How might these deficiencies be remedied? In the public policy arena, greater public awareness has stimulated demand for scientific research to inform the decision-making process. To manage effectively the boundary between science and policy, and to serve society, the regulatory agencies must work in close partnership with the public, the scientific community, and with stakeholders. This collaborative approach has the potential to increase legitimacy, credibility, and salience at the same time by fusing the production of scientific knowledge or consensus with the political and social processes underlying a given policy issue. Two key steps are essential, and though these already fall within the existing policies of the regulators, it is arguable that their implementation is waning considerably. Firstly, a fully collaborative approach to regulation and an increase in transparency in the role of the regulator are essential. This will ensure that decision makers and stakeholders have a familiarity and 
sense of ownership over scientific data, and its interpretation, used in the shaping of policy. Secondly, policy development and the business of regulation must be fully justified, open, accurately documented, and fully disassociated from unsubstantiated opinion and ideology. Dialogue helps ensure transparency, which must be measured by audit and independent review. That evidence will appear in the scientific journals, properly documented and subject to the rigours of blind peer review. Science has its own professional standards and a universal Code of Practice for scientific conduct to which all investigators must adhere. Regulators must do likewise.

There are now a great many general and specialist scientific and technical journals. These accommodate both the pure and applied sciences, each giving a voice to the community of investigators working in the field of waste management. The sometimes turbulent world of waste management enjoys a substantial research input from investigators all around the world. Those research findings are however often dissociated from the regulatory process which dips selectively into the pool of knowledge to support though not to shape policy. Funding may support highly selective research that provides additional 'post-policy evidence' while the policy itself remains critically immune from challenge or review. The architects of our legislation can be deliberately blind to even strong evidence that does not sit well with preconceived ideology. Claiming a 'weight of evidence' based on a highly selective, skewed or limited data set turns a cognitive and subjective process into something that connotes a purely rational and objective process [4].
A knowledge-based approach to policy making is not new, and many governments profess to be fully committed to this [5]. Notwithstanding, evidence-based policymaking may be more apparent than real. Key decisions are often made incorporating various degrees of uncertainty. This may be unavoidable, though it should be a temporary situation lasting only until science can provide further information. This is an iterative process. Decisions must be reviewed and moderated in response to evolving knowledge and experience. To secure these goals, to reassure and support stakeholders, scientists and the public alike, Parliament and the Commissioners of its regulatory agencies must declare once again their policy and approach to regulation, and affirm the standards by which those policies will be managed at every level. This should ensure that the need for an effective scientific foundation is properly met at all times, is managed effectively and applied objectively and with uniformity. Anything less would be unacceptable.

\section{REFERENCES}

[1] R. Barnes, "Environmental science $v$ environmental policy: a personal view from middle England" Environmental Scientist, vol. January/February, pp 14-16, 2007.

[2] J. I. Blenkharn, "Lowering standards of clinical waste management: do the hazardous waste regulations conflict with the CDC's universal/standard precautions?" J. Hosp. Infect., vol. 62, pp. 467472, April 2006.

[3] D. Michaels, "Scientific evidence and public policy" Am. J. Public. Health., vol. 95, Suppl. 1, pp. S5-S7, July 2005.

[4] S. Krimsky, "The weight of scientific evidence in policy and law" Am. J. Public. Health., vol. 95, Suppl. 1, pp. S129-S136, July 2005.

[5] D. C. Wilson, N. A. Smith, N. C. Blakey, and L. Shaxson, "Using research-based knowledge to underpin waste and resources policy" Waste Manag. Res., vol. 25, pp. 247-256, June 2007. 